\title{
BAPNE FIT: Neuromotricity and Body Percussion in Physical Activity and Sport Sciences
}

\author{
Francisco Javier Romero-Naranjo \\ Department of Educational Innovation, Faculty of Education, University of Alicante, San Vicente del Raspeig, Alicante, Spain.
}

\begin{abstract}
How to cite this paper: Francisco Javier Romero-Naranjo. (2022). BAPNE FIT: Neuromotricity and Body Percussion in Physical Activity and Sport Sciences. The Educational Review, USA, 6(2), 37-44. DOI: 10.26855/er.2022.02.001
\end{abstract}

Received: December 28, 2021

Accepted: January 20, 2022

Published: February 4, 2022

Corresponding author: Francisco Javier Romero-Naranjo, Department of Educational Innovation, Faculty of Education, University of Alicante, San Vicente del Raspeig, Alicante, Spain. Email: bapne.central@gmail.com

\begin{abstract}
In this publication, we introduce a new model of sports learning called Bapne Fit which proposes a protocol of physical and cognitive activities. Its exercise protocol is linked to endurance training, as well as perceptual and coordination skills for the development of the body schema with a clear link to the stimulation of executive functions. Neuromotor activities combined with the use of weights for wrists and ankles, weight vests, Step, stroboscopic goggles and special visual plates of the BAPNE method provide a new way of working both physical and cognitive aspects based mainly on the double task. The activities are not choreographed and are based on neuromotor skills, so they are classified into three levels of intensity to be applicable to all audiences. The low, medium and high intensities work continuously on dissociation, coordination and laterality. All of them require a continuous use of working memory, attentional network, inhibitory control, decision making and processing speed, among other aspects. In this article, we present an approach to BAPNE FIT.
\end{abstract}

\section{Keywords}

Neuromotricity, BAPNE FIT, Body percussion, Sport training, Physical education

\section{Introduction}

Sports training has evolved increasingly over the last 50 years thanks to new technologies and advances in neuroscience (Rajšp \& Fister, 2020). Some focus on gaining muscle mass, others on gaining flexibility and still others on endurance development with the aim of improving cardiovascular performance. In this case, BAPNE FIT proposes cross-cutting activities to work not only physically but also cognitively with low, medium and high intensity activities. The BAPNE method works with different types of groups and through scientific publications tries to organize and systematize in an academic way all the transversal possibilities that this discipline has. BAPNE is a method of cognitive, socioemotional, psychomotor and neurorehabilitative stimulation based on neuromotor skills. It currently has nearly 200 articles and more than 30 books on this subject that already exceed 800 academic citations (Serna et al., 2018).

Globally, all publications can be classified into four major groups:

1) Foundational Publications. These are those in which we justify the introduction to certain topics such as Neuromotricity (Andreu-Cabrera \& Romero-Naranjo, 2021), Executive functions (Romero-Naranjo, 2018), etc., with specific practical activities for each area. In this block are all BAPNE manuals, Review articles, Bibliometric (Serna et al., 2018) or foundation articles, etc.

2) Publications of a didactic nature. It is articulated through the production of articles or manuals that have the objective of providing practical resources for each specialty of the methodology. The design of activities of each of them are completely different (Romero-Naranjo, 2013-2021) but have as initial basis The initial or basic protocol is the first basis. 
3) Research Design Publications. These are articles that specify how we are going to investigate, what test we pass, how long the investigation lasts, how many times a week we intervene, how the activities are organized, etc. (Jiménez-Molina et al,. 2017; Fabra-Brell, 2017).

4) Publications with Statistical Results. These are articles that present small results given that we currently do not have longitudinal data. BAPNE has only small investigations that hover between 60 and 140 subjects per investigation (Álvarez-Morales \& Romero-Naranjo, 2019; Arnau-Mollá, 2020; Carretero-Martínez, 2014; Cozzutti et al., 2017; Latre-Nava, 2019; Torró-Biosca, 2019; Moral-Bofill et al., 2020). We know that the number of subjects to be evaluated is still small. The common line of all these investigations is the "Executive functions" of which we have doctoral theses and specific articles about it. Without longitudinal research it cannot be demonstrated that BAPNE has conclusive results (at present we only have pilot studies).

In BAPNE, each pedagogical or therapeutic area has its own didactic autonomy so that the activities are completely different from one area to another. Body percussion from the point of view of neuromotor skills in BAPNE provides very diverse and completely different protocols depending on the area in which it is worked. The justification for this statement is that each area has very different purposes and therefore completely different activities from each other. Some of them are listed below:

1) BAPNE BASIC. Contribution of basic resources linked to Neuromotor skills at the initial level (Romero-Naranjo, 1998). These are the very general basic resources that are taught in any 12-hour introductory course.

2) BAPNE COGNITIVE SOLFEGGIO. Protocol of precise activities for learning the basic concepts of musical language through the "Baobab Garden” (Romero-Naranjo, 2018; Romero-Naranjo, 2020).

3) BAPNE FIT. Protocol of activities linked to Physical Activity Sciences through the use of "Steps", "Weight vest or ballasted", "Weights for wrists and ankles" as well as "stroboscopic goggles", virtual reality glasses, small balls, cones and visuo-spatial BAPNE plates (Romero-Naranjo, 2019).

4) BAPNE for Math. The activities are exclusive for students between 3 and 6 years old. Its main objective is to work mainly on learning properties and relationships in relation to sizes, geometric shapes, direction and sense, high-bottom, over-low, over-short, long-short, equality and difference, classifications, etc. (Romero-Naranjo, 2021)

5) BAPNE for Kids. Teaching resources for babies from 6 months of age based on theory of mind. (Romero-Naranjo, 2019).

6) BAPNE for Children. Protocol of activities ranging from 3 to 6 years of age with the objective of learning the first motor skills focused on fine and gross psychomotor skills. (Romero-Naranjo, 2017).

7) BAPNE for Alzheimer's. Alzheimer's disease has very specific characteristics so the activities are perfectly adapted to cognitive impairment. (Romero-Naranjo, 2018)

8) BAPNE for Parkinson's. The activities of this subject are linked to movement disorders and improvement of motor coordination. (Romero-Naranjo, 2018).

9) BAPNE and Body Expression. This line of work provides very specific resources for the expression of movement from various resources that are in connection with the sciences of physical activity and sport as well as musical learning. (Romero-Naranjo, 2019).

What is the reason for such different protocols? The answer is very clear. The training of a basketball player is very different from that of a marathon runner, a Formula One runner and, if we go much further, from that of a musician, a psychologist or a kindergarten teacher. For this reason, the neuromotor activities BAPNE linked to the sciences of activity and sport (BAPNE FIT) have nothing to do with those of Alzheimer's, 6-month-old children or Cognitive solfège, etc.

\section{Materials and Methods}

\subsection{BAPNE and Physical Activity and Sport Sciences}

Since 2008 the University of Alicante has within the subjects of Physical Education and Sport Sciences the subject of body percussion in a continuous way. Body percussion is the art of striking the body to produce various types of sounds for didactic, therapeutic, anthropological and social purposes. In both the world of musical traditions and the world of the performance, body percussion has had various roles, which can be classified into its uses, meanings and functions which are specific to each individual culture (Romero-Naranjo, 2013).

Through a very diverse design of activities, given that the objectives are completely different from other students of other university careers, such as music education or early childhood education, we provide a training methodology with very specific and exclusive characteristics created by Dr. Romero-Naranjo. 


\subsection{What is BAPNEFIT?}

It is an exclusive activity protocol linked to resistance training, as well as perceptual-coordination skills for the development of the body scheme with a clear link to cognitive stimulation. Non-choreographed activities based on neuromotricity with body percussion use a variety of objects to stimulate the body and mind. It is one of the few methodologies that mixes motor training with cognitive stimulation.

\subsection{What tools does the BAPNE FIT methodology use?}

It requires a large room and the use of various objects that are listed below:

- Step (various types)

- Wrist and ankle weights (various types)

- Weight vest (weight vest)

- BAPNE visuo-spatial plates

- Stroboscopic goggles

- Virtual reality glasses

- Balls with different textures, weights and sizes.

- Bozu

- Cones and symbols for spatial orientation

- Elastic bands (different types)

BAPNE FIT has through its 800 activities three levels of intensity (low, medium and high). The activities can be performed bipedal or seated, individually or in groups. BAPNE FIT has eight levels of learning articulated through a very specific glossary of activities.

\subsection{What are BAPNE FIT activities like?}

Neuromotor activities almost always involve "dual task" exercises and are classified into three main levels of intensity and therefore difficulty.

\subsubsection{Low intensity.}

A. Coordination and resistance activities with weights on the wrists (Figure 1).

B. Coordination and resistance activities with weights on the wrists and elastic band on the thighs (Figure 2).

C. Coordination and resistance activities with weights on the wrists, weights on the ankles and elastic band on the thighs.
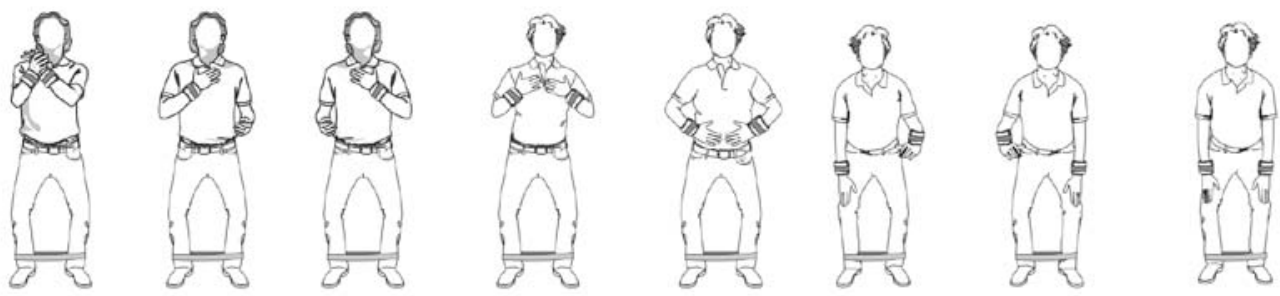

Figure 1. Low intensity neuromotor activity model.
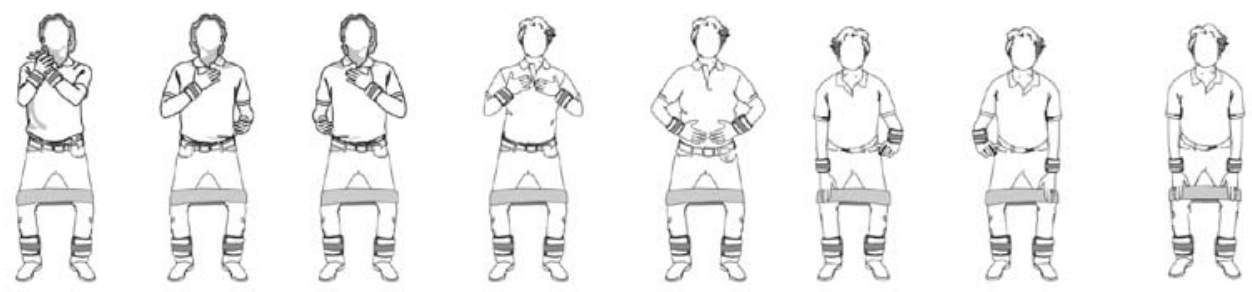

Figure 2. Low intensity neuromotor activity model with weights on the ankles and elastic band on the thighs. 


\subsubsection{Medium intensity}

A. Coordination and resistance activities with weights on the wrists with a low height Step (Figure 3).

B. Coordination and resistance activities with weights on wrists and elastic band on thighs and low height Step (Figure 4)

C. Coordination and resistance activities with weights on the wrists, weights on the ankles, elastic band on the thighs and low height Step.
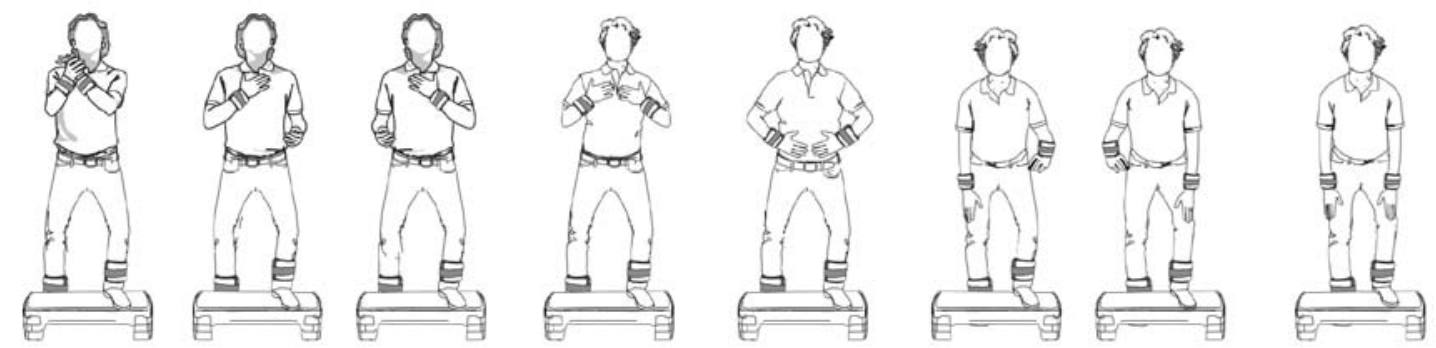

Figure 3. Medium intensity neuromotor activity model with Step I.
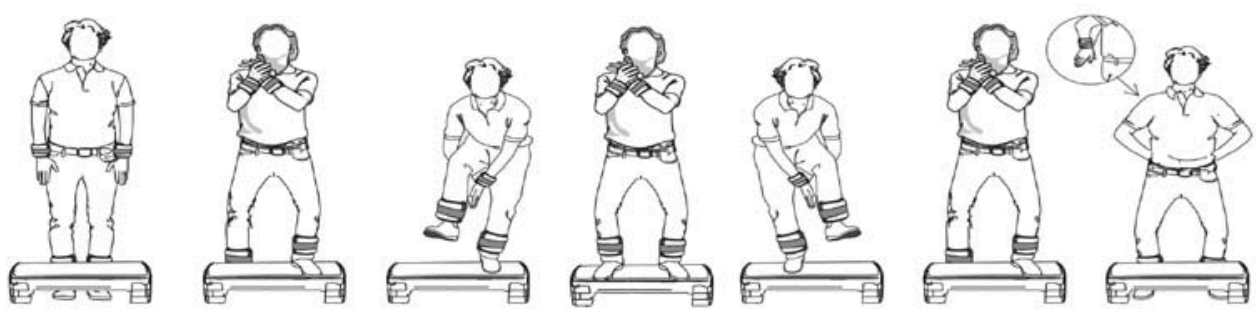

Figure 4. Medium intensity neuromotor activity model with Step II.

\subsubsection{High intensity}

1) Coordination and resistance activities with weight vest, wrist weights, and medium and high Step (Figure 5).

2) Coordination and resistance activities with weight vest, weights on the wrists and ankles, elastic band and Step of medium and high height.
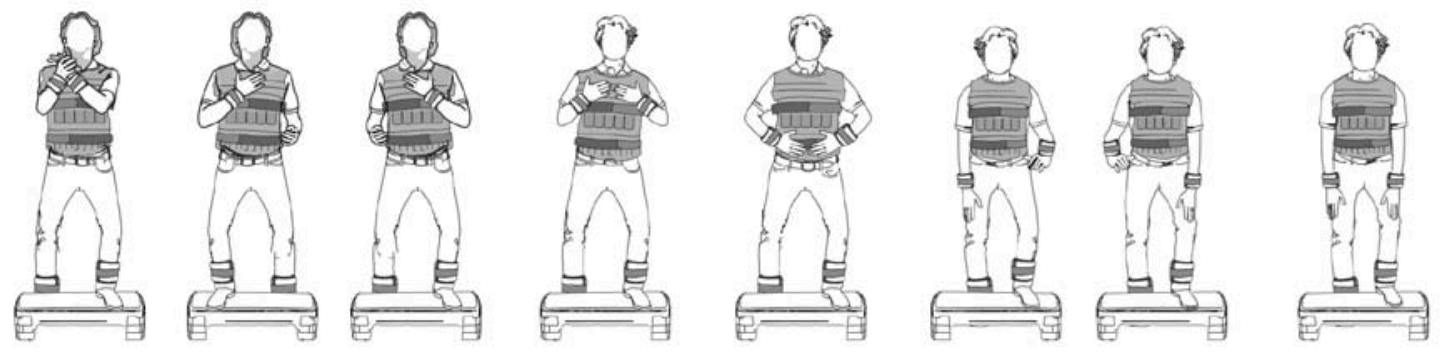

Figure 5. High intensity neuromotor activity model with weight vest.

* Each of these intensity levels always includes the use of visuo-spatial BAPNE plates, balls, stroboscopic goggles, depending on the type of activities to be performed.

\subsection{How is learning articulated?}

The form of learning is both circular and frontal. 


\section{A. Circular.}

Much of these activities focus on circular learning where the manager changes his or her position in the circle throughout the session.

\section{B. Frontal.}

This type of location in space is mainly linked to the reading of the visuo-spatial BAPNE sheets, which is done through the projection of these cards.

\subsection{What is worked in BAPNE FIT?}

In BAPNE FIT, we can work both kinesthetic and cognitive aspects based mainly on cognitive functions and executive functions. We proceed to justify some specific aspects.

\subsubsection{Physical aspects}

The activities are focused to work mainly on the following points:

- Attitude and postural control

- Spatial-temporal structuring

- Laterality

- Static and dynamic balance

- Segmental coordination (hand-eye, hand-eye, foot-eye)

- General dynamic coordination

- Dissociation

- Basic motor skills

\subsubsection{Cognitive Aspects}

- Cognitive functions (memory, language, praxias, spatial orientation, visuospatial ability, attentional network, social cognition and executive functions).

- Executive functions (processing speed, working memory, inhibition, verbal fluency, dual task, cognitive flexibility, branching and decision making).

\subsubsection{Emotional Aspects}

Emotional balance through the CASA emotions (Curiosity, Admiration, Security and Joy) following R. Aguado's model.

\subsubsection{Social Aspects}

The overall group activity generates very important bonding points. Lowen argues that the three forms of rootedness are generated through the gaze because I watch you, the hands because I touch you, and the feet because I move.

\section{Management aspects of the activity}

Another novelty of BAPNE FIT is that it requires a specialized trainer to lead the classes since they are not choreographed activities and require a continuous change of the motor activity. Another aspect to highlight is that there are spaces called "You are the Teacher" where some of the participants are invited to manage some specific activities. The objective is to work on executive functions in relation to planning, dual tasks and decision making. This aspect serves to connect with socioemotional learning and with the evaluation of emotions. It is important to keep in mind that there are different models such as Berrocal's, Bizquerra's, Salovey and Mayer's, Aguado's, etc. In our case, we follow Roberto Aguado's model based on CASA and TRAM emotions.

\section{Conclusions}

The activity protocols according to the disciplines being worked on (Alzheimer Disease, are completely different in the BAPNE method). BAPNE FIT is a novel proposal because it has an activity protocol never seen before. The use of Step with weights on the wrists and ankles while performing movements with non-choreographed body percussion brings a new dimension. The activities have several levels in which not only the physical difficulty is increased (weighted vests), but also the cognitive one where the double task is always present. Activities that require continuous use of working memory, attentional network, inhibitory control, decision making and processing speed are always present. BAPNE FIT promotes all the dimensions of the human being that has through its books published on this discipline in 2019 brings more than 800 activities at a practical level. 


\section{References}

Álvarez-Morales, L. J. and Romero-Naranjo, F. J. (2019). Pilot study into executive functions with muslim and christian pupils in the city of Ceuta using body percussion. The European Proceedings of Social \& Behavioural Sciences, 60(92), $742-750$. https://dx.doi.org/10.15405/epsbs.2019.04.02.92.

Andreu-Cabrera, E. and Romero-Naranjo, F. J. (2021). Neuromotricidad, Psicomotricidad y Motricidad. Nuevas aproximaciones metodológicas. (Neuromotricity, Psychomotricity and Motricity. New methodological approaches). Retos, 42, 924-938. https://doi.org/10.47197/retos.v42i0.89992.

Arnau-Mollá, A. F. and Romero-Narnjo, F. J. (2020). Quantitative study on selective attention in children aged 8-9 years through bodypercussion. European Proceedings of Social and Behavioural Sciences, 84(6), 50-60. https://doi.org/10.15405/epsbs.2020.05.6.

Carretero-Martínez, A., Javier Romero-Naranjo, F., Pons-Terres, J. M., and Crespo-Colomino, N. (2014). Cognitive, visual-spatial and psychomotor development in students of primary education through the body percussion - BAPNE method. Procedia Social and Behavioral Sciences, 152(Octuber 7, 2014), 1282-1287. https://doi.org/10.1016/j.sbspro.2014.09.363.

Castelló-Juan, B., Antón-Suay, M. T., Flores-Morales, N., Vicedo-Reche, M., and Romero-Naranjo, F. J. (2019). Evaluating executive functions in primary school children in Alicante using body percussion. The European Proceedings of Social \& Behavioural Sciences, 60(70), 559-566. https://dx.doi.org/10.15405/epsbs.2019.04.02.70.

Conti, D. and Romero-Naranjo, F. J. (2015). Singing BAPNE®: Body percussion and voice as a didactic element. Procedia - Social and Behavioral Sciences, 197(July 25, 2015), 2498-2505. https://doi.org/10.1016/j.sbspro.2015.07.322.

Cozzutti, G., Guaran, F., Blessano, E., and Romero-Naranjo, F. J. (2017). Effects on executive functions in the BAPNE method; A study on 8-9 years old children in Friuli Venezia Giulia, Italy. Procedia - Social and Behavioral Sciences, 237(February 21, 2017), 900-907. https://doi.org/10.1016/j.sbspro.2017.02.126.

Crespo Colomino, N. and Romero Naranjo, F. J. (2014). Body percussion and dyslexia. Theoretical and practical contribution through the BAPNE method. Procedia - Social and Behavioral Sciences, 132(May 15, 2014) 686-690. https://doi.org/10.1016/j.sbspro.2014.04.373.

Crespo-Colomino, N., Pons-Terrés, J. M., Romero-Naranjo, F. J., Romero-Naranjo, A. A., and Liendo-Cárdenas, A. (2014). Atención y dislexia: Una propuesta de trabajo mediante la didáctica de la percusión corporal-Método BAPNE. (Attention and dyslexia: A proposal of work through the didactics of body percussion-BAPNE Method). En XII Jornadas de Redes de Investigación en Docencia Universitaria. El reconocimiento docente: innovar e investigar con criterios de calidad (pp. 1092-1105). Universidad de Alicante.

Crespo-Colomino, N., Romero-Naranjo, F. J., Pons Terres, J. M., Carretero-Esteve, A., and Perez-Bravo, E. (2014). Perceived sensations related to the state of flowing factors produced during the performance of cognitive stimulation: Exercises through the didactics of the body percussion BAPNE method. Procedia - Social and Behavioral Sciences, 152(October 7, 2014), 1201-1206. https://doi.org/10.1016/j.sbspro.2014.09.299.

Fabra-Brell, E. and Romero-Naranjo, F. J. (2017). Body Percussion: Social Competence Between Equals Using the Method BAPNE in Secondary Education (Design Research). Procedia - Social and Behavioral Sciences, 237.

Fabra-Brell, E. and Romero-Naranjo, F. J. (2017). Social competence between equals through body percussion according to method BAPNE in secondary students. Procedia-Social and Behavioral Sciences, 237(February 21, 2017 ), 829-836. https://doi.org/10.1016/j.sbspro.2017.02.179.

González Sánchez, O. S., Romeu López, C. E., and Romero-Naranjo, F. J. (2019). Pilot study of executive functions in elderly adults in care homes. The European Proceedings of Social \& Behavioural Sciences, 60(95), 770-776. https://dx.doi.org/10.15405/epsbs.2019.04.02.95.

Jauset Berrocal, J. A., Tripovic, Y., and Romero Naranjo, F. J. (2014). El método BAPNE y su repercusión en las capacidades cognitivas. (The BAPNE method and its impact on cognitive abilities). En XII Jornadas de Redes de Investigación en Docencia Universitaria. El reconocimiento docente: innovar e investigar con criterios de calidad (pp. 1672-1686). Universidad de Alicante.

Jiménez-Molina, J. B., Vicedo-Cantó, E., Sayago-Martínez, R., and Romero-Naranjo, F. J. (2017). Evaluating attention, socioemotional factors and anxiety in secondary school students in Murcia (Spain) using the BAPNE® method. Research protocol. Procedia - Social and Behavioral Sciences, 237(February 21, 2017), 1071-1075. https://doi.org/10.1016/j.sbspro.2017.02.157.

Latre-Nava, S., Martínez-Fernández, X., Rodríguez-Masafrets, A., Puigdevall-Cayuela, A., Torre, G., Finestres-Alverola, J., and Romero-Naranjo, F. J. (2019). Cognitive stimulation in adolescents at risk of exclusion using the BAPNE® method. The European Proceedings of Social \& Behavioural Sciences, 60(62), 489-499. https://dx.doi.org/10.15405/epsbs.2019.04.02.62.

Moral Bofill, L., Vicedo Molla, F., and Romero Naranjo, F. J. (2020). Estudio piloto de variables socio-emocionales, ansiedad y flow en alumnos de grado profesional de música mediante actividades BAPNE. (Pilot study of socio-emotional variables, anxiety and flow in professional music students through BAPNE activities). Educatio Siglo XXI, 38(2 Jul-Oct, 2020), 193-212. 
https://doi.org/10.6018/educatio.432971.

Moral-Bofill, L. (2015). The BAPNE Method as a School Intervention and Support Strategy to Improve the School Environment and Contribute to Socioemotional Learning (SEL).

Piqueres Juan, I., Sánchez González, E., Serna Domínguez, M., Trives Martínez, E. A., García Sala, M., and Romero Naranjo, F. J. (2018). Aproximación a la justificación de la atención selectiva a través de la percusión corporal-Método BAPNE. (Approach to the justification of selective attention through body percussion-BAPNE Method). En C. Guerrero Romera, \& P. Miralles Martínez (Eds.), Innovación y Modelos de Enseñanza-Aprendizaje en la Educación Superior (pp. 141-152). Edit.um.

Piqueres-Juan, I., Sarmiento-Alienes, S., Sánchez-González, E., and Romero-Naranjo, F. J. (2019). Pilot study into sustained and selective attention using the BAPNE method. The European Proceedings of Social \& Behavioural Sciences, 60(93), 751-759. https://dx.doi.org/10.15405/epsbs.2019.04.02.93.

Pons-Terrés, J. M., Romero-Naranjo, A. A., Romero-Naranjo, F. J., Crespo-Colomino, N., and Liendo-Cárdenas, A. (2014). Estimulación de la atención dividida: Didáctica de la percusión corporal-Método BAPNE. (Stimulation of divided attention: Didactics of body percussion-BAPNE Method). En XII Jornadas de Redes de Investigación en Docencia Universitaria (pp. 1040-1050). Universidad de Alicante.

Pons-Terres, J. M., Romero-Naranjo, F. J., Carretero-Martinez, A., and Crespo-Colomino, N. (2014). Perceptions towards wellness and life quality through body percussion - BAPNE method and cognitive stimulation in elderly people. Procedia - Social and Behavioral Sciences, 152(October 7, 2014), 1108-1113. https://doi.org/10.1016/j.sbspro.2014.09.283.

Rajšp, A.; Fister, I., Jr. (2020). A Systematic Literature Review of Intelligent Data Analysis Methods for Smart Sport Training. Appl. Sci., 10, 3013. https://doi.org/10.3390/app10093013.

Romero Naranjo, F. J. (2013). Science \& art of body percussion: a review. Journal of Human Sport \& Exercise, 8(2), $442-457$. https://doi.org/10.4100/jhse.2012.82.11.

Romero Naranjo, F. J. (2014b). Body percussion. Theoretical practical foundation (10th ed., Vols. 1-5). Body music-Body Percussion Press.

Romero Naranjo, F. J. (2015). Fundamentos de la percusión corporal como recurso para la estimulación cognitiva, atención y memoria- Método BAPNE. (Fundamentals of body percussion as a resource for cognitive stimulation, attention and memory BAPNE Method). En Investigación y Propuestas Innovadoras de Redes UA para la Mejora Docente (pp. 2149-2163). Universidad de Alicante.

Romero Naranjo, F. J. (2019a). Africa for children: Neuromotricity and executive functions. 2-99 años (1st ed.). Body music-Body Percussion Press.

Romero Naranjo, F. J. (2019b). BAPNE for Alzheimer - Neuromotricity and executive functions. Body music-Body Percussion Press.

Romero Naranjo, F. J. (2019c). BAPNE for Babies - Neuromotricity and executive functions. Body music-Body Percussion Press.

Romero Naranjo, F. J. (2019d). BAPNE for children. Canons and rhythms: Neuromotricity and executive functions. 2-99 años (1st ed.). Body music-Body Percussion Press.

Romero Naranjo, F. J. (2019e). BAPNE for children \& gross motor skills: Neuromotricity and executive functions. 2-99 años (8th ed.). Body music-Body percussion Press.

Romero Naranjo, F. J. (2019f). BAPNE for Parkinson - Neuromotricity and executive functions. Body music-Body Percussion Press.

Romero Naranjo, F. J. (2019g). BAPNE for Seniors - Neuromotricity and executive functions. Body music-Body Percussion Press.

Romero Naranjo, F. J. (2019h). BAPNE \& expresión corporal - Neuromotricity and executive functions. 2-99 años. Body music-Body Percussion Press.

Romero Naranjo, F. J. (2019i). Cognitive solfege: Neuromotricity and executive functions. 2-99 años (10th ed.). Body music-Body percussion.

Romero Naranjo, F. J. (2019j). BAPNE FIT. Body percussion and neuromotricity in physical activity and sport sciences. Body music-Body percussion.

Romero Naranjo, F. J. (2021a). Neuromotricity and Mathematics. 3/4 years. Body music-Body Percussion Press.

Romero Naranjo, F. J. (2021b). Neuromotricity and Mathematics. 4/5 years. Body music-Body Percussion Press.

Romero Naranjo, F. J. (2021c). Neuromotricity and Mathematics. 5/6 years. Body music-Body Percussion Press.

Romero-Naranjo, A. A. and Romero-Naranjo, F. J. (2013). La percusión corporal como recurso terapéutico. (Body percussion as a therapeutic resource). En XI Jornadas de Redes de Investigación en Docencia Universitaria: Retos de futuro en la enseñanza superior: Docencia e investigación para alcanzar la excelencia académica (pp. 1734-1747). Universidad de Alicante.

Romero-Naranjo, A. A., Liendo-Cárdenas, A., Romero-Naranjo, F. J., and Menargues Marcilla, A. (2014). Percusión corporal y TDAH en el método BAPNE. Introducción metodológica. (Body percussion and ADHD in the BAPNE method. Methodological introduction). En XII Jornadas de Redes de Investigación en Docencia Universitaria. El reconocimiento docente: Innovar 
e investigar con criterios de calidad (pp. 1717-1729). Universidad de Alicante.

Romero-Naranjo, A. A., Romero-Naranjo, F. J. Moral-Bofill, L. (2016). Body Percussion and Team Building through the BAPNE Method. SHS Web of Conferences, 26(3).

Romero-Naranjo, F. J. (2014a). Body percussion and memory for elderly people through the BAPNE method. Procedia - Social and Behavioral Sciences, 132(May 15, 2014), 533-537. https://doi.org/10.1016/j.sbspro.2014.04.349.

Romero-Naranjo, F. J. (2020). Body percussion in the physical education and sports sciences. An approach to its systematization acording to the BAPNE method. International Journal of Innovation and Research in Educational Sciences, 7(5), 2349-5219.

Romero-Naranjo, F. J. and Andreu-Cabrera, E. (2021d). Neuromotricity as a new paradigm. Journal of Human Sport and Exercise. https://doi.org/10.14198/jhse.2023.181.16.

Romero-Naranjo, F. J. and Sayago-Martínez, R. (2021e). Music motor control and dual task. Handsball Change as a musical-motor paradigm. Erpa International Congresses on Education, Sakarya, Turkey.

Romero-Naranjo, F. J. and Sayago-Martínez, R. (2021f). Rhythm, Cognitive Solfege and Body percussion. Proposal for educational innovation. Erpa International Congresses on Education, Sakarya, Turkey.

Romero-Naranjo, F. J., Crespo-Colomino, N., Liendo-Cardenas, A., Pons-Terres, J. M., and Carretero-Martinez, A. (2014). Drugs and body percussion: Rehabilitation therapy using the BAPNE method. Procedia - Social and Behavioral Sciences, 152(October 7, 2014), 1128-1132. https://doi.org/10.1016/j.sbspro.2014.09.287.

Romero-Naranjo, F. J., Pons-Terrés, J. M., Romero-Naranjo, A. A., Crespo-Colomino, N., Liendo-Cárdenas, A., Jauset-Berrocal, J. A., Quarello, A., Pezzutto, E., and Tripovic, Y. (2014). La percusión corporal como estímulo para los alumnos con déficit de atención y concentración. (Body percussion as a stimulus for students with attention and concentration déficits). En XII Jornadas de Redes de Investigación en Docencia Universitaria. El reconocimiento docente: innovar e investigar con criterios de calidad (pp. 1120-1130). Universidad de Alicante.

Romero-Naranjo, F.J. (2019). Cuerpo, movimiento y emoción: BAPNE. (Body, movement and emotion: BAPNE). Cuadernos de pedagogía.

Ros-Silla, E., Valcarcel-Marsa, S., Jaikel-Arce, D., Berlai, S., Giglio, R., Payro-Escobar, A., and Romero-Naranjo, F. J. (2019). Attention in conservatoire students using body percussion following the BAPNE method. The European Proceedings of Social \& Behavioural Sciences, 60(57), 448-455. https://dx.doi.org/10.15405/epsbs.2019.04.02.57.

Serna Domínguez, M., Romero Naranjo, F. J., Sánchez González, E., Piqueres de Juan, I., García Sala, M., and Trives Martínez, E. A. (2018). Investigación en percusión corporal.: Estudio bibliométrico de la percusión corporal hasta 2017. (Research in body percussion: a bibliometric study of body percussion up to 2017). En C. Gerrero Romera \& P. Miralles Martínez (Eds.), Innovación y modelos de enseñanza-aprendizaje en la educación superior (pp. 40-51). Edit.um.

Torró-Biosca, R., Aparici-Mínguez, F., Arnau-Mollá, A. F., Ulate-Orozco, R. M., Cabrera-Quirós, D. A., and Romero-Naranjo, F. J. (2019). Pilot study into the executive functions of children aged 8-9 BAPNE method. The European Proceedings of Social \& Behavioural Sciences, 60(94), 760-769. https://dx.doi.org/10.15405/epsbs.2019.04.02.94.

Trives Martínez, E. A., Romero Naranjo, F. J., Serna Domínguez, M., Sánchez González, E., Piqueres de Juan, I., and García Sala, M. (2018). Aproximación al estudio de los precursores del movimiento y la percusión corporal en educación. (Approach to the study of the precursors of movement and body percussion in education). En P. Miralles Martínez \& C. Guerrero Romera (Eds.), Metodologías Docentes Innovadoras en la Enseñanza Universitaria (pp. 355-367). Edit.um.

Trives-Martínez, E. A. and Vicente-Nicolás, G. (2013). La percusión corporal y los métodos didácticos musicales. (Body percussion and musical didactic methods). En XI Jornadas de Redes de Investigación en Docencia Universitaria: Retos de futuro en la enseñanza superior: Docencia e investigación para alcanzar la excelencia académica (pp. 1748-1759). Universidad de Alicante.

Trives-Martínez, E. A., Romero-Naranjo, F. J., Pons-Terrés, J. M., Romero-Naranjo, A. A., Crespo-Colomino, N., Liendo-Cárdenas, A., Jauset-Berrocal, J. A., Quarello, A., Pezzutto, E., and Tripovic, Y. (2014). Los métodos didáctico musicales y la atención en relación al movimiento. (Musical didactic methods and attention in relation to movement). En XII Jornadas de Redes de Investigación en Docencia Universitaria. El reconocimiento docente: innovar e investigar con criterios de calidad (pp. 1066-1079). Universidad de Alicante. 